\author{
Associate Professor Mehmet Oğuz ARSLAN, PhD \\ E-mail: moarslan@anadolu.edu.tr \\ Hatice ALTINOK, PhD Candidate \\ E-mail: haltinok@anadolu.edu.tr \\ Department of Public Finance \\ Faculty of Economics and Administrative Sciences \\ Anadolu University
}

\title{
A SYSTEM DYNAMICS MODEL OF INCOME DISTRIBUTION BETWEEN LABOR AND CAPITAL FOR TURKEY ${ }^{\mathrm{a}}$
}

\begin{abstract}
System dynamics approach models a system of variable interactions and is able to explain causal links and feedback loops between those variables. In this context, system dynamics can be applied to analyzing income distribution dynamics of an economy. In this study, we perform an income distribution analysis of the Turkish economy using Goodwin's growth cycle model as the main system dynamics model in economics. The findings of the study show that the distribution of GDP between the labor and the capital has a cyclical dynamic feature for Turkey in the 1965-2015 period.
\end{abstract}

Keywords: System dynamics, Goodwin's growth cycle model, income distribution, NetLogo, Turkish economy.

\section{JEL Classification:C63, E32, 015}

\section{Introduction}

Goodwin's growth cycle model is an important system dynamics model in macroeconomics. Goodwin's model employs a mathematical model in ecology, the Lotka-Volterra (the predator-prey) model, to analyze income distribution dynamics between the labor and the capital in a capitalist economy. Besides, Goodwin asserts that the struggle between the labor and the capital for obtaining more national income has a cyclical character. In this study, whether an income struggle between the labor and the capital is cyclical in the Turkish economy in the period of 1965-2015 within the framework of Goodwin's model is investigated.

This paper consists of five main parts. The first part introduces system dynamics approach briefly. Then, the second part gives Goodwin's growth cycle model with some details. The third part of the study represents the related literature shortly. The fourth part is the core part of the study and analyses the income

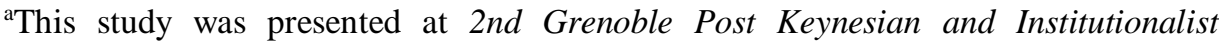
Conference which was held in Grenoble, France in December 7-9, 2017.

DOI: $10.24818 / 18423264 / 52.4 .18 .16$ 
Mehmet Oğuz Arslan, Hatice Altinok

distribution dynamics of Turkey using Goodwin's growth cycle model. The fifth part concludes the study.

\section{System dynamics in brief}

Santa Fe Institute defines system dynamics as "one approach to the study of complex systems over time that focuses on stocks, flows, and feedbacks often described by differential equations" (Complexity Explorer). System dynamics was developed by Jay M. Forrester to understand the dynamics in an industrial process with a feedback theory and to identify mean reasons for failure that occurred in past processes (Forrester 1961).

A simple system dynamics model consists of some stocks and flows with some connections among them as feedback loops. Stocks generally collect the information or material that flows into the system or out of the system. Flows refer flows of information or material enter and exit stocks of a system. Feedbacks are transmissions and returns of information about the level of information or material which are collected in stocks of a system (Radzicki 2009).

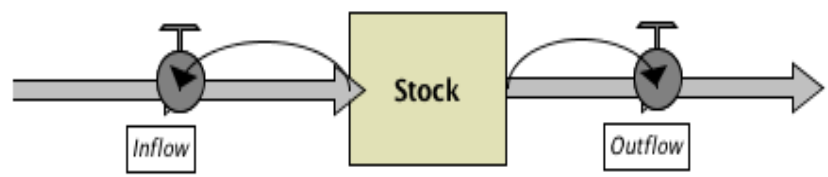

Figure 1: Stock-flow variables in system dynamics

The connections between stock and flow variables depicted in Fig. 1. In this figure, it is seen that stock variable indicates the difference between inflow and outflow. The taps determine functions that regulate flows in the system. We denote the relation between stock and flow variables in a system dynamics model mathematically as follow (Barlas 2007, Sterman 2000):

$$
\begin{gathered}
\frac{d(\text { Stock })}{d t}=\text { NetChangeinStock }=\operatorname{Inflow}(t)-\text { Outflow }(t) \\
\Rightarrow \operatorname{Stock}(t)=\operatorname{Stock}\left(t_{0}\right)+\int_{t_{0}}^{t}(\operatorname{Inflow}(s)-\text { Outflow }(s)) d s
\end{gathered}
$$

System dynamics is one of the five stages of systems thinking. These stages are; (a) defining the problem, (b) displaying causal loop, (c) building system dynamics, (d) maintaining opinions with the causal loop which are decided before, and (e) developing model simulation and interpreting the results and deciding policy proposals (Rowell and Wormley 1997). 
A System Dynamics Model of Income Distribution between Labor and Capital for Turkey

System dynamics approach is used for analyzing many ecological (biological), physical and social systems. One of the most distinctive applications of system dynamics is the predator-prey model of ecological systems. The predator-prey model is also known as the Lotka-Volterra model with reference to its developers A. J. Lotka and V. Volterra. The Lotka-Volterra equations are a pair of first order, non-linear, differential equations that describe the dynamics of biological systems in which two species interact, as a predator and a prey (Wilensky 2005).

The Lotka-Volterra model has four main assumptions:

- Prey has an unlimited food supply in nature.

- Prey's only threat is predator hence, a decrease in prey population affects predator's.

- Predator's only food supply is prey, and that the growth rate of predator population depends on the amount of prey caught. Hence, an increase in predator population affects predator population.

- The encountering probability of predators with prey is jointly proportional to the sizes of both populations.

The Lotka-Volterra equations are:

$$
\begin{aligned}
& \frac{d x}{d t}=x(+a-b y) ; \quad a, b>0 \\
& \frac{d y}{d t}=y(-c+d x) ; c, d>0
\end{aligned}
$$

Eq. (2) gives the change in prey population over time and Eq. (3) gives the change in predator population over time, where; $x$ denotes prey population, $y$ denotes predator population, $a$ denotes a constant growth rate of prey population, $b$ denotes the density of predator population, $c$ denotes growth rate of predator population, and $d$ denotes the density of prey population.

The cycles of predator and prey populations over time according to solutions of the Lotka-Volterra equations is given in Figure 2.

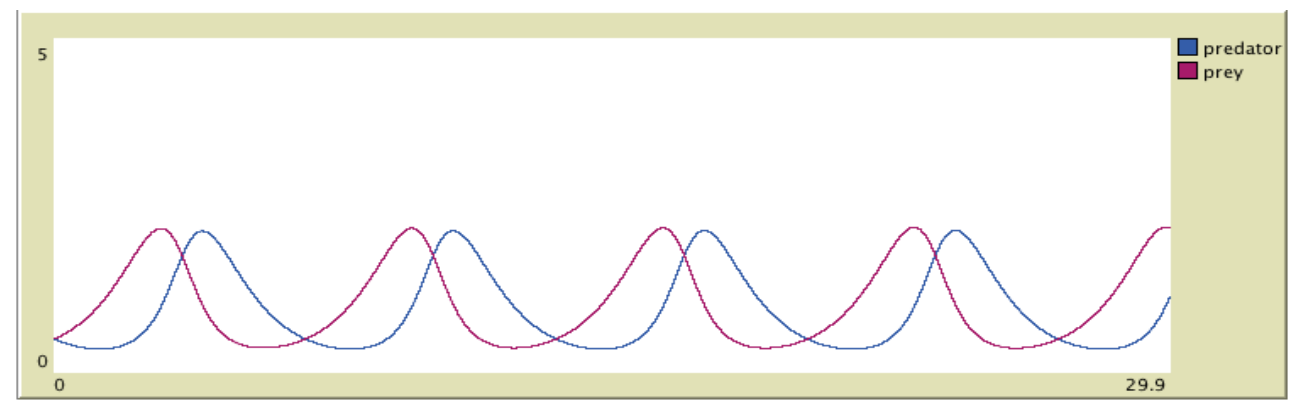

Figure 2: Predator and prey populations over time 
Mehmet Oğuz Arslan, Hatice Altinok

Here, it should be pointed out two important points (Weber 2005). The first is that the period of cycle $(T)$ is calculated by the formula:

$$
T=\frac{2 \pi}{\sqrt{a c}}
$$

Secondly, prey population goes ahead $1 / 4$ period against predator population as clearly seen above.

The phase diagram of the Lotka-Volterra model is given Figure 3.

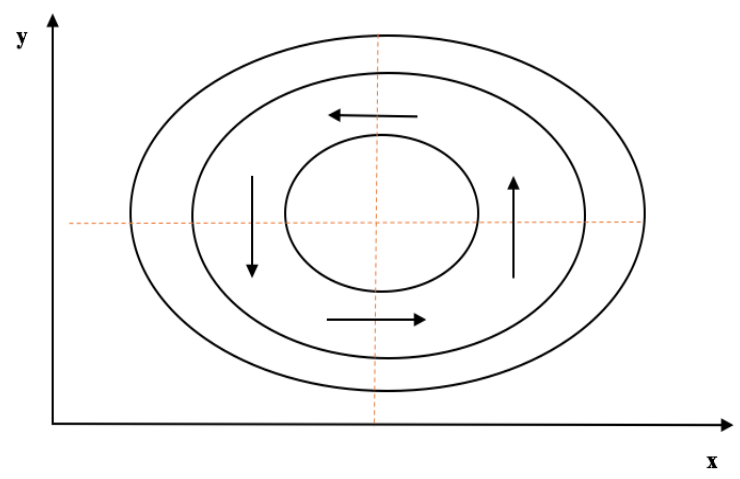

Figure 3: The phase diagram of the Lotka-Volterra equations

\section{Goodwin's growth cycle model}

According to Radzicki (2008), "system dynamics is a dynamic, disequilibrium approach to modeling complex systems that portrays human behavior and microlevel decision making as it actually is rather than as it might be in an idealized state". In his point of view, a system dynamicist accepts that the macro behavior of a system is caused by its microstructure. Radzicki (2008) also asserts that complex/system dynamicists share the same perspective about the world with Post Keynesian and Institutionalist economists, and there are certainly strong links between the feedback loops and the stock-flow analysis promoted by complex/system dynamicists and the stock-flow coherent analysis suggested by some Post Keynesian economists.

As a Post Keynesian economist, Richard M. Goodwin was one of the leading economists who interested in the application of system dynamics approach to economics. Goodwin's studies between the 1940s and 1960s are likely the most influential works on this issue. Among them, Goodwin's (1967) growth cycle model is of special importance. This model more explicitly draws on ecological predecessors in the form of the predator-prey model of Lotka and Volterra. It is the workers with their wage demands who play the role of the 'predators', with their wage demands bringing about the reversal of the investment-driven capitalist expansion in Goodwin's model (Rosser 2009). 
A System Dynamics Model of Income Distribution between Labor and Capital for Turkey

Goodwin (1967) stated that "Volterra's problem of the symbiosis of two populations -partly complementary, partly hostile- is helpful in the understanding of dynamical contradictions of capitalism, especially when stated in a more or less Marxian form".

In Goodwin's growth cycle model, the income share of capital (the employment rate) $v$ is represented as the prey, and the income share of labor $u$ is represented as the predator. Goodwin's growth cycle model is given by the following two differential equations:

$$
\begin{aligned}
& \frac{d x}{d t}=x(+a-b y) \Rightarrow \frac{d v}{d t}=\left\{\left[\frac{1}{\sigma}-(\alpha+\beta)-\frac{u}{\sigma}\right\} v\right. \\
& \frac{d y}{d t}=y(-c+d x) \Rightarrow \frac{\mathrm{d} u}{d t}=\{-(\alpha+\gamma)+\rho v\} u
\end{aligned}
$$

The variables in the differential equations are defined as follows: $\sigma$ is the capital-output ratio, $\alpha$ is the growth rate of population, $\beta$ is the growth rate of labor productivity, $\gamma$ is the intersection of Phillips curve, and $\rho$ is the slope of Phillips curve. In addition, $(d v / d t)$ gives net employment rate, and $(d u / d t)$ gives net labor's share. The variables are determined as follow:

- Natural growth rate of employment rate, $a=\frac{1}{\sigma}-(\alpha+\beta)$

- The density of employment rate, $b=\frac{1}{\sigma}$

- Natural growth rate of employment's share, $c=(\alpha+\gamma)$

- The density of labor's share, $d=\rho$

The differential equations (5) and (6) are depicted using NetLogo System Dynamics Modeler (Wilensky 1999) in Fig. 4. The feedback loops in the model can be seen easily in this figure. 


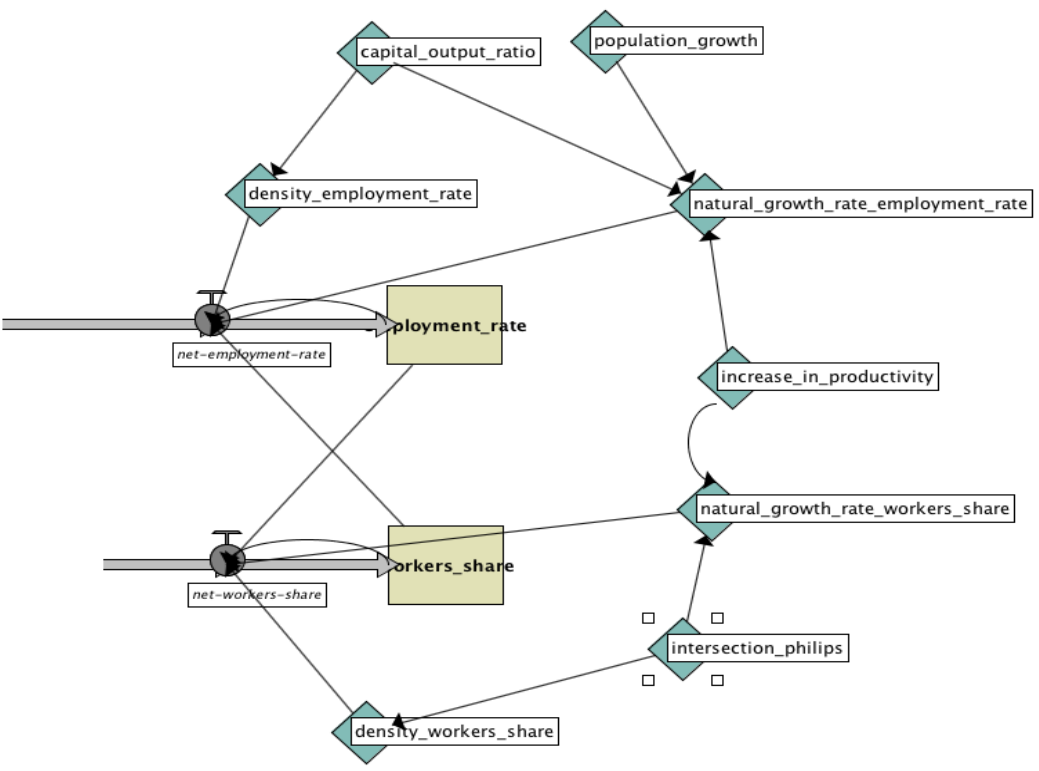

Figure 4: The structure of system dynamics of Goodwin's growth cycle model

As it is seen in Figure 4, employment rate and labor's share indicate the stock of the system whereas net employment rate and net labor's share indicate the flows of the system. Stocks interact with flows and variables. These interactions resulted in an increase or a decrease in employment rate and labor's (workers') share.

The initial values of the system variables for the cyclical movement of Goodwin's model are:

- Employment rate, $v=0.60$

- Labor's share, $u=0.40$

- Capital-output ratio, $\sigma=1.00$

- Growth rate of population, $\alpha=0.01$

- Growth rate of labor productivity, $\beta=0.01$

- Intersection of Phillips curve, $\gamma=1.00$

- Lag value, $d t=0.0001$

After running the model using those values, we have reached $T=6.31$ for the system. This value refers to a specific term, e.g. years, months. The cyclical behavior of the model over time is shown below. 
A System Dynamics Model of Income Distribution between Labor and Capital for Turkey

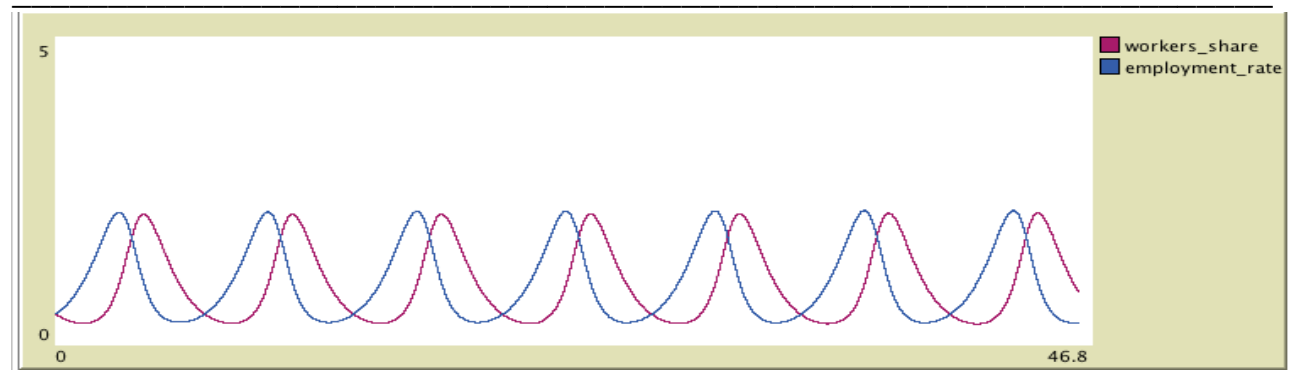

Figure 5: The cyclical behavior of Goodwin's growth cycle model

The phase diagram of Goodwin's growth cycle model is given in Fig. 6. It should be noted that this figure resembles the phase diagram of the Lotka-Volterra equations in Fig. 3.

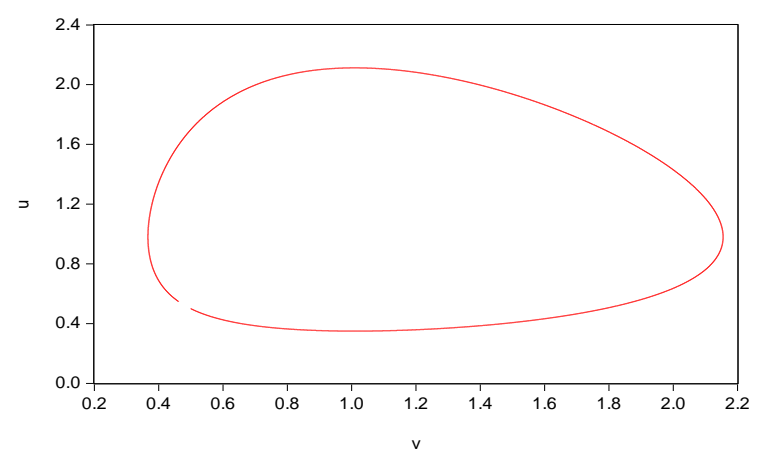

Figure 6: The phase diagram of Goodwin's growth cycle model

The trajectory of the phase diagram depends only on the initial values of employment rate and labor's share of income. If the system encounters an intervention, it will have difficulty to sustain its trajectory and will be forced to go a new trajectory (Harvey 2000).

\section{Related literature}

Goodwin's growth cycle model has been a very attractive model for economists, mathematicians, even physicists for 50 years. Hence, a vast literature on theoretical examinations, versions, and extensions of Goodwin's growth cycle model has appeared since then. Since our study focuses on a country, we pay attention to the studies that have country-specific applications of Goodwin's growth cycle model. Among them, for example, Harvie (2000) is an earlier study that tests the validity of Goodwin's model using the annual data of 10 OECD countries between 1959-1994. Harvie (2000) found out that the cycles produced for those countries resemble the cycle of Goodwin's model to a certain degree but the econometric results for those countries are not statistically significant. Weber 
Mehmet Oğuz Arslan, Hatice Altinok

(2005) investigated the validity of Goodwin's model for Germany using the data which was used in Harvie (2000). In this study, two different system dynamics model were implemented and the runs of these models yielded the conclusion that cyclical behaviors of German economy fitted into Goodwin's model to a large extent but the econometric results were not statistically significant just as in Harvie (2000).

Flaschel, Kauermann, and Teuber (2005) tested Goodwin's model for the U.S. economy using the data between 1959-1994 and concluded that the U.S. application of Goodwin's model produces cycles that have longer phase diagram than original Goodwin's model does. Also, Barbosa-Filho and Taylor (2006) analyzed the U.S. economy in a Goodwinian perspective using the data between 1948-2002 and asserted that real wage and labor productivity dynamics over the cycle are the main driving force behind the distributive profit squeeze. BarbosaFilho and Taylor (2006) stated that both the real wage and labor productivity growth at about 0.57 percent per quarter keeps the labor share stable.

Mohun and Veneziani (2006) applied Goodwin's model for the U.S. corporate economy using the data from 1948 to 2004, and identified short run de-trended Goodwin cycles but no long run cycles. Moura and Riberio (2013) tested Goodwin's growth cycle model for Brazil using the annual data from 1981-2009 and observed only a partial agreement with Goodwin's model. Moura and Riberio (2013) concluded that Goodwin's model must be improved in order to become a viable representation of real-world data. Konstantakis, Michaelides, and Mariolis (2014) employed an extended Goodwin-Keynes type model to test German economy for the 1991-2007 period and came to the conclusion that the empirical results of the study were satisfactory.

5. The analysis of the income distribution dynamics of Turkey using Goodwin's growth cycle model

\subsection{The variables and the structure of the model}

We define stock and flow equations in the application of Goodwin's growth cycle model to the Turkish economy as defined by Goodwin (1967), Harvie(2000), and Utama (2012) as follow:

a) The level of the growth rate of labor productivity $d a / d t=\alpha a, a$ is labor productivity, $\alpha$ is the growth rate of labor productivity and must be greater than 0 .

b) The growth rate of population-level $d N / d t=\beta N, N$ is labor supply, $\beta$ is the growth rate of population and must be greater than 0 .

c) The change rate of capital stock level $d K / d t=I-\delta K, I$ is investment, $\delta$ is depreciation rate, $K$ is capital stock.

d) The change rate of real wage $d w / d t=(-\gamma+\rho v) w, \quad \gamma$ and $\rho$ are the coefficients of the linear Phillips curve, $v$ is employment rate, $w$ is real wages. 
A System Dynamics Model of Income Distribution between Labor and Capital for Turkey

We also define auxiliary variables to make stock variables of our application more expressive as defined by Goodwin (1967), Harvie (2000), and Utama (2012) as follow:

a) The output $Y=K / \sigma$, is equal to the accelerator coefficient of capital.

b) The investment $I=\pi$, according to Goodwin, all profits $(\pi)$ turn into the investment $(I)$.

c) The profit rate $\pi=Y-w L, w L$ is wages bill.

d) The labor $L=Y / a$

e) The wages' share $u=w / a$

f) The employment rate $v=L / N$

The definitions given above is depicted in Figure 7.

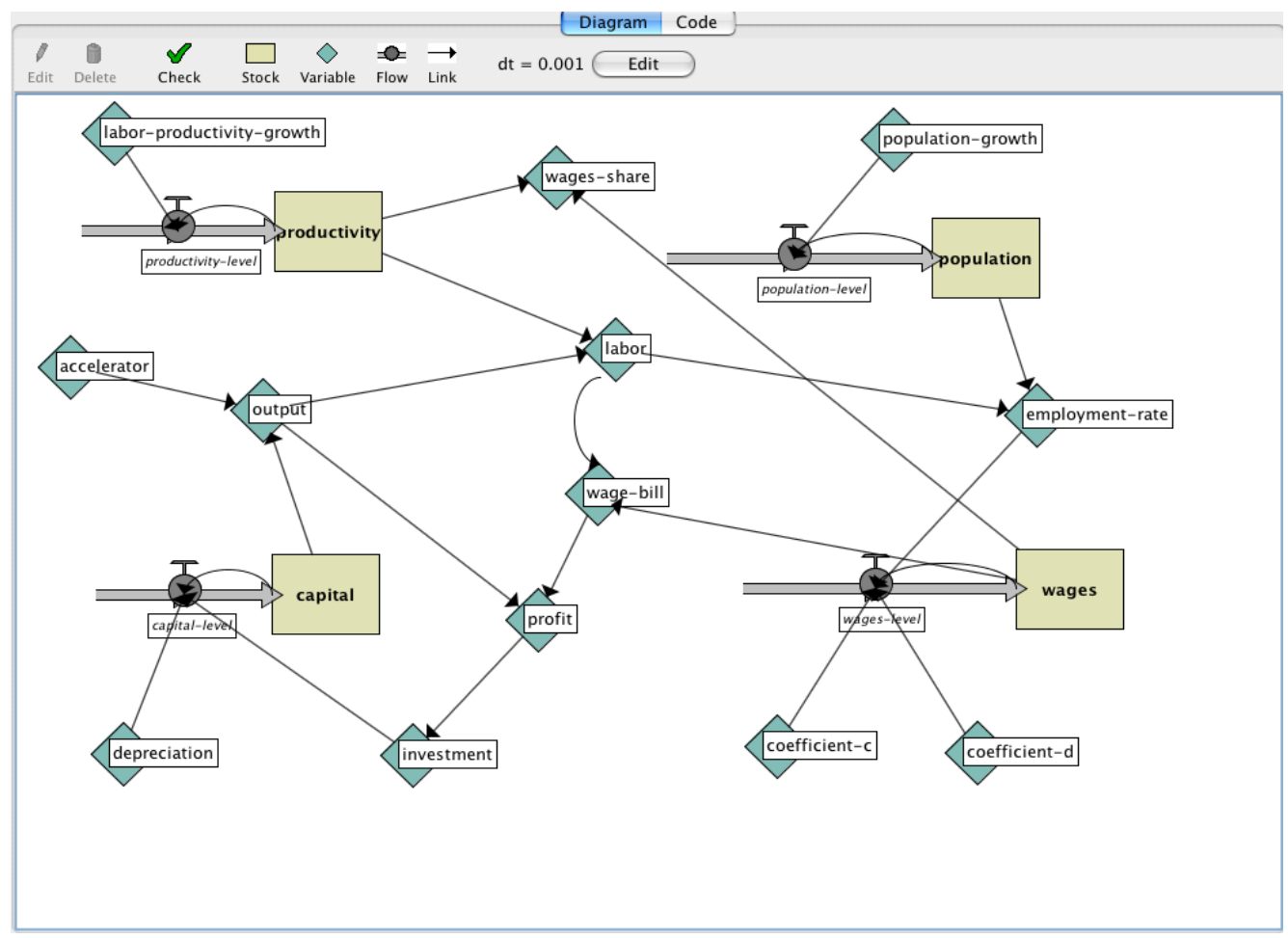

Figure 7: The structure of system dynamics of Goodwin's growth cycle model for Turkey

\subsection{The initial values of the model variables}

In our application, we use the data between 1965-2015 for the Turkish economy. We wipe away 6 digits in the values of capital stock and population to converge original Goodwin's growth cycle model. This simplification does not 
Mehmet Oğuz Arslan, Hatice Altinok

change the period of system's trajectory and general characteristic of the system. The initial values of the system variables are given below.

- Labor productivity, $a=1.2$

- Capital stock, $K=2000$

- Population, $N=31$

- Real wages, $w=0.94$

- Depreciation rate, $\delta=0.05634$

- Accelerator coefficient, $\sigma=2.83$, also means capital-output ratio.

- Growth rate of labor productivity, $\alpha=0.026935$

- Growth rate of population, $\beta=0.01085$

- Coefficient-c of Phillips curve $\gamma=12.26097$

- Coefficient-d of Phillips curve $\rho=2,873596$

We found the coefficients $\alpha, \beta, \gamma, \rho$ using some econometric methods (e.g. OLS, FMOLS, ARDL) (The tables of the results are given in Annex). Also, $a, K, N$ and $w$ are taken as the initial values of 1965. The accelerator rate and the depreciation rate are the mean values of the 1965-2015 period. The period of the system is found as 3.19 years and calculated according to the formula:

$$
T=\frac{2 \pi}{\sqrt{(\alpha+\gamma)\left(\frac{1}{\sigma}-(\alpha+\beta)\right)}}
$$

\subsection{The results of the run of the model}

The real trajectory of the employment and workers' shares rates for Turkish economy between 1965-2015 is depicted below.

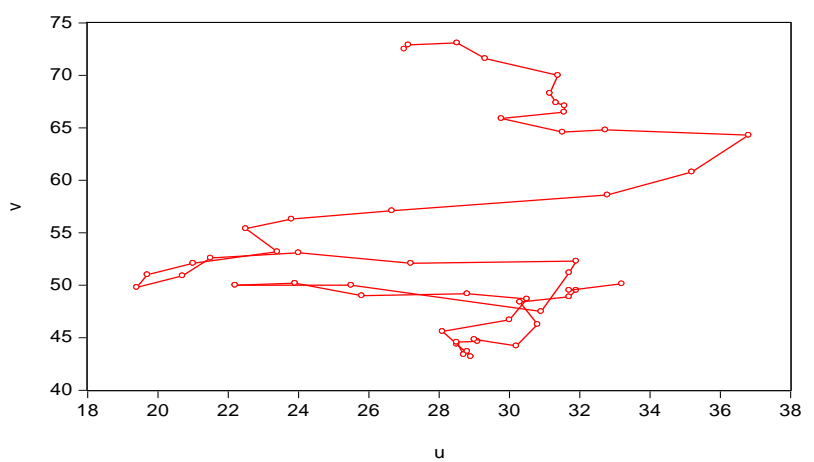

Figure 8: Goodwin's growth cycle model for the Turkish economy in the long run

This figure shows that there is no single cycle for the Turkish economy in this period. However, we identify two sub-cycles in the figure in the periods of 19651986 and 1986-2015. 
A System Dynamics Model of Income Distribution between Labor and Capital for Turkey

We produced the cyclical behavior of Goodwin's growth cycle model for Turkey between 1965-2015 by using the System Dynamics Modeler of NetLogo platform as seen in Fig. 9.

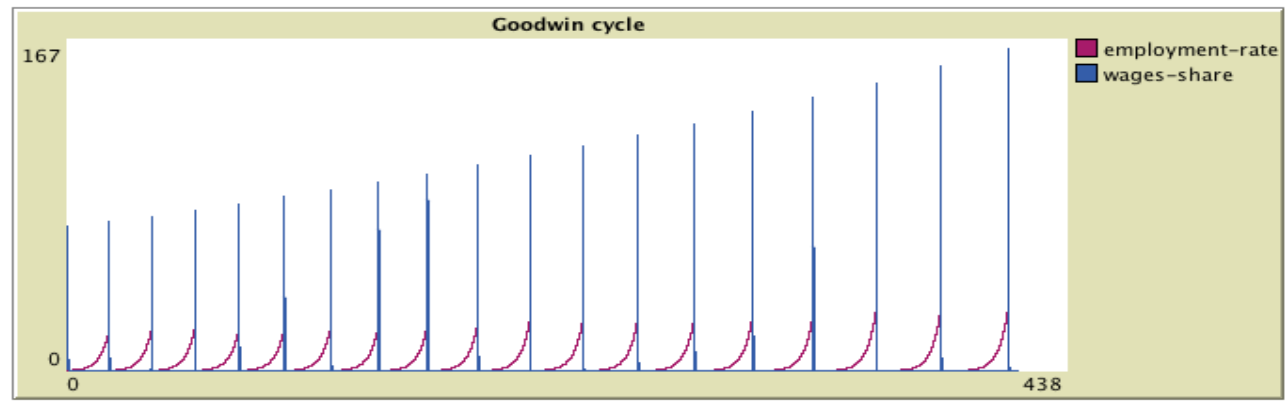

Figure9: The Goodwinian cyclical behavior of Turkish economy between 1965-2015

In Figure 9, although the employment rate and wages share converge to zero, they never become zero. The cycle in the beginning of the period repeats itself at the frequency of 3.19 years. Also, the Goodwinian growth cycle of our model is shown in Fig. 10.

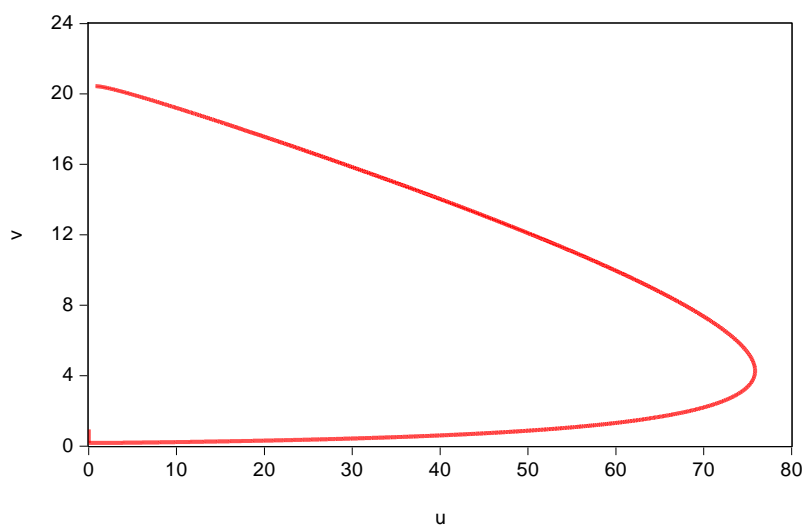

Figure 10: The Goodwinian growth cycle of Turkish economy between 19652015

Though the original Goodwin's growth model has an ellipse-shaped cycle, we produced a little different cycle shape as seen in Fig. 10. We can say that this mismatch comes from the difference between the results of a mathematical model 
Mehmet Oğuz Arslan, Hatice Altinok

(the original Goodwin's model) and its real-world application. Although Goodwin's growth cycle model ideally takes the values of $u$ and $v$ between 0 and 1, our model takes these values greater than Goodwin's model's. Nevermore, this shape shows expressly that the income distribution struggle between the labor and the capital has a dynamic cyclical character for the Turkish economy in the 19652015 period.

\subsection{Interpretation of the model results for the Turkish economy}

In the Turkish economy, the main economic crises that occurred between 1965-2015 corresponded to the periods of the Goodwinian cyclical changes in national income shares between the labor and the capital. We can say that the Turkish economy became so fragile during the periods of the cyclical changes in income struggle between the labor and the capital. In these periods, it is seen that an economic crisis occurred if some other factors were also influential.

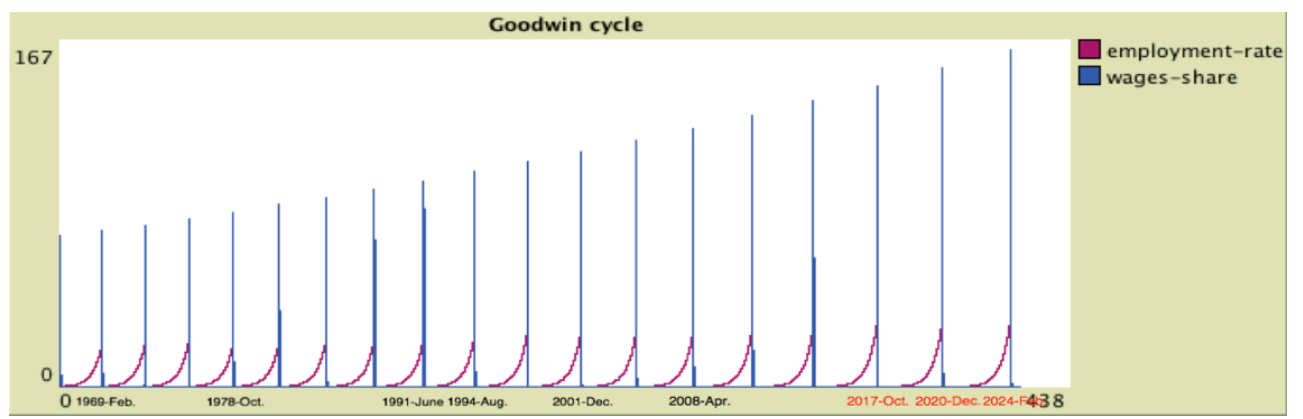

Figure 11: Economic crises and the growth cycles in the Turkish economy over time

Our Goodwin model developed for Turkey seems successful in explaining the economic crises experienced in the past. In addition, the results of this model could be used to predict future economic conditions. According to the model, the likelihood of a crisis in the periods of cyclical change will be higher than in normal years in the future. From this point of view, the probability of an economic crisis approximately in October 2017, December 2020, February 2024, April 2027 and June 2030 is higher than in normal times. In this respect, it is a clear result of our Turkish application that Goodwin's growth cycle model does not only explains the growth fluctuations of the past but has also a great potential for predicting possible economic crises that will happen in future years. 
A System Dynamics Model of Income Distribution between Labor and Capital for Turkey

\section{Conclusion}

From the perspective of the Goodwinian system dynamics, it is seen that the income distribution struggle between the labor and capital has a dynamic cyclical character in the Turkish economy in the 1965-2015 period, as assumed by Goodwin's growth cycle model for any capitalist economy. When this situation is interpreted for the Turkish economy, we achieved very interesting results. In the Turkish economy, the main economic crises that took place during this 51-year period coincided with the periods of the Goodwinian cyclical changes in national income shares between the labor and capital. In other words, the Turkish economy became rather fragile during the periods of cyclical changes in the struggle between the labor and capital for obtaining more national income. In these periods, it is seen that an economic crisis occurred when some other factors were also influential. Hence, our (enhanced) Goodwin model that developed for the Turkish economy seems successful in explaining the economic crises of Turkey experienced in the past. In addition, the results of the model can be used to predict future economic crises of the Turkish economy.

\section{REFERENCES}

[1] Barbosa-Filho, N. H., Taylor, L. (2006), Distributive and Demand Cycles in the US Economy - A Structuralist Goodwin Model; Metroeconomica, 57 (3), 389411;

[2] Barlas, Y. (2011), System Dynamics: Systemic Feedback Modeling for Policy Analysis; System 1, 59, 1131-1175;

[3] Complexity Explorer (2017), Glossary, https://www.complexityexplorer.org/explore/glossary (Retrieved in 12.10.2017);

[4] Flaschel, P, Kauermann, G., Teuber, T. (2005), Long Cycles in Employment, Inflation and Real Unit Wage Costs, Qualitative Analysis and Quantitative Assessment; American Journal of Applied Sciences 2, 13, 69-77;

[5] Forrester, J. W. (1961), Industrial Dynamics; Cambridge, Mass.: MIT Press; [6] Goodwin, R. M. (1967), A Growth Cycle. In C. H. Feinstein (ed.). Socialism, Capitalism, and Economic Growth; Cambridge, Mass.: Cambridge University Press, 54-58;

[7] Harvie, D. (2000), Testing Goodwin: Growth Cycles in Ten OECD Countries; Cambridge Journal of Economics. 24, 349-376;

[8] G. (2005), Unit-root Testing against the Alternative Hypothesis of up to

Structural Breaks; Journal of Time Series Analysis, 26 (1), 143-147;

[9] Konstantakis, K. N., Michaelides, P. G., Mariolis, T. (2014), An

Endogenous Goodwin-Keynes Business Cycle Model: Evidence for Germany (1991-2007);Applied Economics Letters, 21 (7), 481-486;

[10] Maki, D. (2012), Tests for Cointegration Allowing for an Unknown Number of Breaks; Economic Modelling, 29, 2011-2015; 
Mehmet Oğuz Arslan, Hatice Altinok

[11] Mohun, S., Veneziani, R. (2006), Goodwin Cycles and the U.S. Economy, 1948-2004; MPRA Paper, University Library of Munich; [12] Moura, N. J., Riberio, M. B. (2013), Testing the Goodwin Growth-cycle Macroeconomic Dynamics in Brazil. Physica A: Statistical Mechanics and its Applications; 392 (9), 2088-2103;

[13] Radzicki, M. J. (2009), System Dynamics and Its Contribution to Economics and Economic Modeling; In Robert A. Meyers (ed.). Encyclopedia of Complexity and Systems Science, New York: Springer;

[14] Radzicki, M. J. (2008), Institutional Economics, Post-Keynesian Economics, and System Dynamics: Three Strands of a Heterodox Braid; In J. T. Harvey and R. F. Garnett (eds.). Future Directions for Heterodox Economics, Ann Arbor, MI: The University of Michigan Press, 156-184;

[15] Rosser, J. B. (2009), Theoretical and Policy Issues in Complex Post Keynesian Ecological Economics; In P. F. Holt, S. Pressman and C. L. Spash (eds.). Post Keynesian and Ecological Economics: Confronting Environmental Issues, Cheltenham: Edward Elgar. 221-236;

[16] Rowell, D., Wormley, D. N. (1997), System Dynamics: An Introduction; New Jersey: Upper Saddle River;

[17] Sterman, J. D. (2000), Business Dynamics: Systems Thinking and Modeling for a Complex World; U.S.A.: McGraw-Hill;

[18] Utama, G. (2012), A New System Dynamics Modeling Framework for the Financial System (With a Case Study of the Keen-Minsky Model); Unpublished doctoral dissertation. Rotterdam: Erasmus University;

[19] Weber, L. (2005), A Contribution to Goodwin's Growth Cycle Model from a System Dynamics Perspective,

http://www.systemdynamics.org/conferences/2005/proceed/papers/WEBER1pdf, (Retrieved in 17.12.2016);

[20] Wilensky, U. (1999), NetLogo, http://ccl.northwestern.edu/netlogo/. Center for Connected Learning and Computer-Based Modeling, Northwestern University, Evanston, IL;

[21] Wilensky, U. (2005), NetLogo wolf sheep predation (system dynamics) model,http://ccl.northwestern.edu/netlogo/models/WolfSheepPredation(SystemDy namics), Center for Connected Learning and Computer-Based Modeling,

Northwestern University, Evanston, IL. 
A System Dynamics Model of Income Distribution between Labor and Capital for Turkey

\section{ANNEX}

\section{Estimation results}

\begin{tabular}{|c|c|}
\hline \multicolumn{2}{|c|}{ OLS results for $\boldsymbol{\alpha}$ ve $\boldsymbol{\beta}$ coefficients } \\
\hline Variable name & Probability \\
\hline $\boldsymbol{\alpha}$ & $0.0000^{*}$ \\
\hline $\boldsymbol{\beta}$ & $0.0000^{*}$ \\
\hline $\begin{array}{l}\text { * indicates that the parameter statistics is } \\
\text { significant at the 5\% level. }\end{array}$ \\
\hline
\end{tabular}

\section{Structural Breaks in Variables}
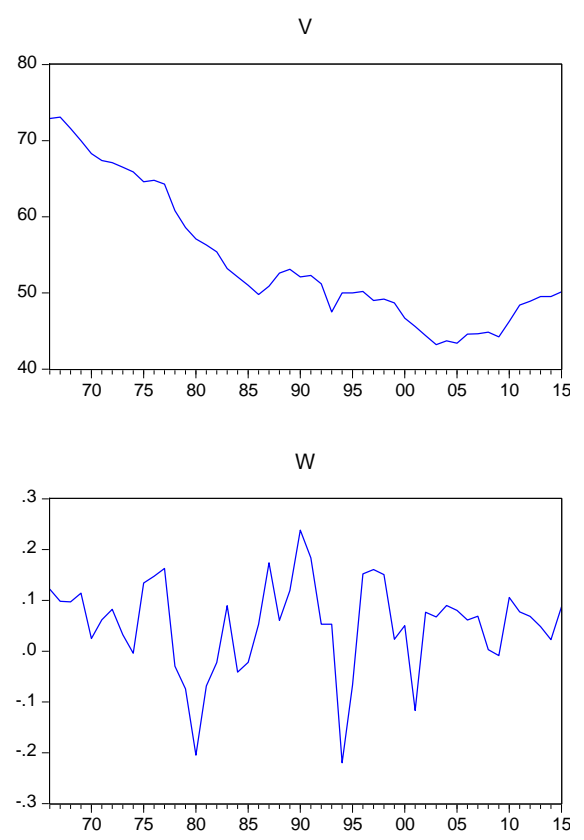

\section{Estimation results}

\begin{tabular}{|c|c|c|c|c|c|c|c|}
\hline \multicolumn{8}{|c|}{ Kapetonios unit root test results and trended model } \\
\hline \multirow[b]{2}{*}{$\begin{array}{l}\text { Variable } \\
\text { Name }\end{array}$} & $\begin{array}{r}\text { Test } \\
\text { Statistic }\end{array}$ & & & & & & \multirow[b]{2}{*}{$\begin{array}{l}\text { First- } \\
\text { difference }\end{array}$} \\
\hline & $\begin{array}{c}\text { Fixed } \\
\text { Model }\end{array}$ & \multicolumn{5}{|c|}{ Break Dates-Fixed Model } & \\
\hline $\mathbf{w}$ & -6.5917 & 1976 & 1985 & 1993 & 2006 & - & $-7.6499 *$ \\
\hline $\operatorname{lnv}$ & -7.2173 & 1975 & 1983 & 1993 & 1998 & 2008 & $-9.1131 *$ \\
\hline \multicolumn{8}{|c|}{ * indicates that stability is significant at the $5 \%$ level. } \\
\hline \multicolumn{8}{|c|}{ Critical values are taken from Kapetonious (2005). } \\
\hline
\end{tabular}


Mehmet Oğuz Arslan, Hatice Altinok

\begin{tabular}{|c|c|c|c|c|c|c|}
\hline \multicolumn{7}{|c|}{$\begin{array}{l}\text { Maki (2012) Cointegration results (dependent variable } w \text {, independent } \\
\text { variable lnv) }\end{array}$} \\
\hline & \begin{tabular}{|l} 
Critical \\
Value
\end{tabular} & $\begin{array}{l}\text { Break } \\
\text { Date } 1\end{array}$ & $\begin{array}{l}\text { Break } \\
\text { Date } 2\end{array}$ & $\begin{array}{l}\text { Break } \\
\text { Date } 3\end{array}$ & $\begin{array}{l}\text { Break } \\
\text { Date } 4\end{array}$ & $\begin{array}{l}\text { Break } \\
\text { Date } 5\end{array}$ \\
\hline Model 3 & $-7.6168^{*}$ & 1982 & 1985 & 1990 & 2000 & - \\
\hline Model 2 & -6.1577 & 1970 & 1979 & 1982 & - & - \\
\hline Model 1 & -6.2760 & 1979 & 1985 & 1989 & - & - \\
\hline Model 0 & $-6.4137^{*}$ & 1985 & 2003 & - & - & - \\
\hline
\end{tabular}

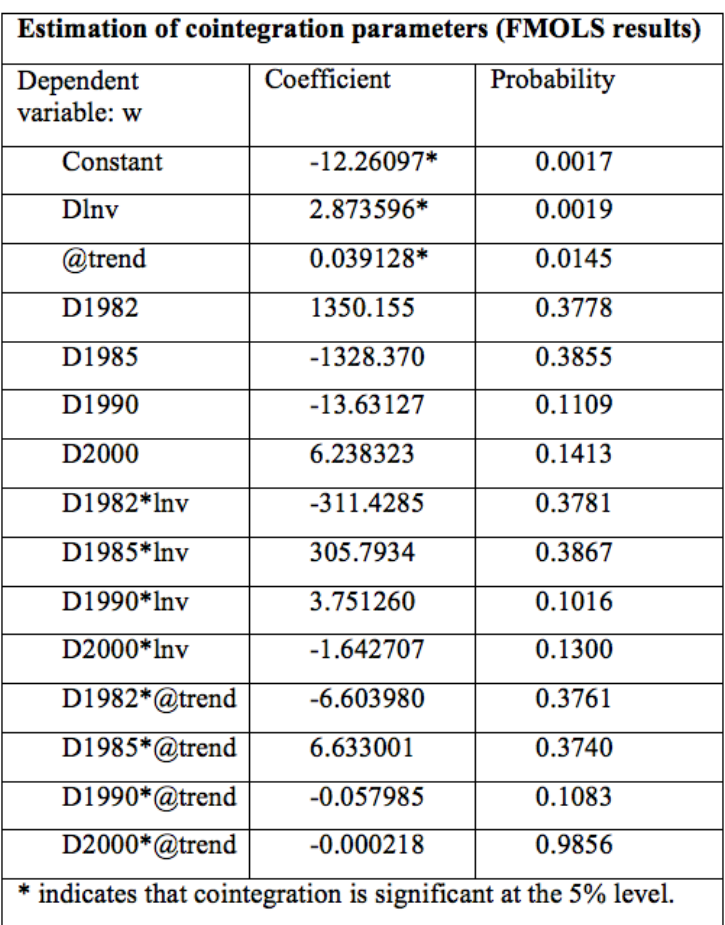

